\title{
Upregulation of RECQL4 expression predicts poor prognosis in hepatocellular carcinoma
}

\author{
JUN LI $^{1}$, JUNFEI JIN ${ }^{1,2}$, MINJUN LIAO ${ }^{3}$, WEI DANG ${ }^{1,2}$, XINHUANG CHEN $^{1}$, \\ YONGFENG WU ${ }^{1}$ and WEIJIA LIAO ${ }^{1,2}$
}

\author{
${ }^{1}$ Laboratory of Hepatobiliary and Pancreatic Surgery, The Affiliated Hospital of Guilin Medical University; \\ ${ }^{2}$ Guangxi Key Laboratory of Molecular Medicine in Liver Injury and Repair, Guilin Medical University, Guilin, \\ Guangxi 541001; ${ }^{3}$ First Clinical Academy, Guangxi Medical University, Nanning, Guangxi 530021, P.R. China
}

Received March 31, 2016; Accepted June 15, 2017

DOI: $10.3892 / 01.2018 .7860$

\begin{abstract}
Previous cDNA microarray experiments revealed that the ATP-dependent DNA helicase Q4 (RECQL4) gene is overexpressed in hepatocellular carcinoma (HCC) tissues. However, the exact role of RECQL4 in HCC remains unknown. The present study aimed to investigate RECQL4 expression in HCC and to analyze the potential clinical implications of RECQL4 expression in HCC patients. The expression of RECQL4 mRNA was assessed in 205 samples of HCC tissues by reverse transcription-quantitative polymerase chain reaction. The results demonstrated that the expression of RECQL4 mRNA in HCC tissues was significantly higher compared with adjacent normal liver tissues $(\mathrm{P}<0.001)$. The level of RECQL4 mRNA expression was associated with high a-fetoprotein (AFP) levels ( $>100 \mathrm{ng} / \mathrm{ml})$, tumor size $(>6 \mathrm{~cm}$ ), and Barcelona Clinic Liver Cancer stage (all $\mathrm{P}<0.05)$. Kaplan-Meier survival analysis indicated that HCC patients with higher levels of RECQL4 expression exhibited significantly shorter disease-free survival (DFS) and overall survival (OS) times compared with those with low levels of expression. Multivariate survival analysis revealed that high RECQL4 expression was a significant independent predictor for DFS [HR, 1.635; 95\% confidence interval (CI), 1.062-2.515; $\mathrm{P}=0.025]$ and $\mathrm{OS}$ (HR, 1.618; 95\% CI, 1.050-2.493; $\mathrm{P}=0.029)$
\end{abstract}

Correspondence to: Professor Weijia Liao, Laboratory of Hepatobiliary and Pancreatic Surgery, The Affiliated Hospital of Guilin Medical University, 15 Lequn Road, Xiufeng, Guilin, Guangxi 541001, P.R. China

E-mail: 1iao288@163.com

Abbreviations: HCC, hepatocellular carcinoma; HR, hazard ratios; $\mathrm{CI}$, confidence intervals; DFS, disease-free survival; OS, overall survival; TNM, tumor-node-metastasis; BCLC, Barcelona Clinic Liver Cancer; AFP, $\alpha$-fetoprotein; HBsAg, hepatitis B surface antigen; ANLT, adjacent noncancerous liver tissues; RT-qPCR, reverse transcription-quantitative polymerase chain reaction

Key words: hepatocellular carcinoma, ATP-dependent DNA helicase Q4, prognosis, diagnosis, biomarker of HCC patients. These data indicated that RECQL4 might be a novel diagnostic and prognostic biomarker for HCC patients.

\section{Introduction}

Hepatocellular carcinoma (HCC) is a leading cause of cancer-associated mortality worldwide. In 2012, there were $\sim 782,500$ new cases and 745,500 incidences of mortality owing to liver cancer, with China alone making up $50 \%$ of this number (1). One issue in HCC management frequently confronted by hepatologist is the accurate prediction of survival outcome, which is necessary in order to provide optimal medical care. A number of staging systems, including clinical Tumor-Node-Metastasis (TNM) stage (2), Cancer of the Liver Italian Program (CLIP) (3) and Barcelona Clinic Liver Cancer (BCLC) (4), are used to predict the prognosis of HCC and stratify patients for treatment. However, patient outcome may be associated not only with disease stage, but also with biological factors. With recent developments in the fields of genomics and proteomics, more relevant prognostic factors are yet to be identified to improve the prognostic strategy of HCC.

In previous genome-wide microarray analysis, a series of genes, including ATP-dependent DNA helicase Q4 (RECQL4), disks large-associated protein 5 (5) and family with sequence similarity 83 member D (6), were significantly upregulated in HCC tissues. RECQL4, as one of the human DNA helicases, serves a critical role in genomic instability and aging processes (7). Genome instability is deemed to have an important part in the multistep development of human cancer (8). Furthermore, interaction has been observed between RECQL4 and proteins involved in genome surveillance (9). Previous studies have demonstrated that mutations in RECQL4 cause three autosomal recessive diseases, Rothmund-Thomson, Rapadilino and Baller-Gerold syndromes (10-12). The potential for unlimited replication is a hallmark of cancer cells (8). RECQL4 serves an essential role in the initiation of DNA replication (13-15) and is directly or indirectly involved in multiple DNA repair pathways, through interactions with diverse repair proteins (16-18). Several studies have revealed that increased RECQL4 expression is observed in sporadic osteosarcoma, prostate carcinogenesis and breast tumorigenesis (19-21). 
Therefore, the role of RECQL4 in human cancer, including $\mathrm{HCC}$, necessitates further investigation.

The aims of the present study were to detect RECQL4 expression in HCC tissue, evaluate the association between RECQL4 expression and patient clinicopathological features and the prognostic significance of RECQL4 expression in HCC.

\section{Materials and methods}

Specimens. A total of 205 pairs of fresh HCC tissues and corresponding adjacent normal liver tissues (ANLT) were obtained from HCC patients who underwent radical curative surgery at the Affiliated Hospital of Guilin Medical University (Guilin, China) between March 2001 and September 2007. The mean age of the patients was 50.22 years (range, 21-74 years). The diagnosis of HCC was based on the results of clinical symptoms, serological, ultrasonography (US), computed tomography, magnetic resonance imaging, pathological examination, according to the primary liver cancer clinical diagnosis and staging criteria. The baseline information, shown in Table I, includes age, gender, family history, hepatitis B surface antigen (HBsAg), a-fetoprotein (AFP), cirrhosis, tumor size and number, BCLC disease stage, metastasis and recurrence. All samples were snap-frozen in liquid nitrogen and stored at $-80^{\circ} \mathrm{C}$ immediately following surgical resection. The inclusion criteria of the present study were as follows: i) Samples were confirmed to be HCC by pathological examination, and the patients underwent radical resection; ii) all patients enrolled have complete background information and follow-up records, including periodic review of liver function, AFP value, imaging information, recurrence time and treatment regimen. Patients diagnosed with cholangiocarcinoma or those that suffered perioperative mortality or with incomplete clinical data were excluded. Additionally, patients who suffered from infectious diseases, autoimmune disease, hematologic disease or used drugs that affect the hematopoietic system within 1 month prior to starting treatment, HIV-positive patients and those who lost contact in the follow-up period were excluded.

The present study was approved by the Ethics Committee of The Affiliated Hospital of Guilin Medical University (Guilin, China) and complies with the Ethical Guidelines of the Declaration of Helsinki. All patients provided written informed consent prior to investigation.

Following surgical resection, the patients with HCC received long-term follow-up via monitoring of serum AFP levels and US examination every 2 months, a chest radiograph every 6 months during the first 2 postoperative years and at 3-6-month intervals thereafter. Computerized tomography or magnetic resonance imaging would be performed if the result of AFP test or US examination were abnormal. Disease-free survival (DFS) time was measured from the date of surgery to the date of recurrence, metastasis, mortality or the last follow-up. Overall survival (OS) time was measured from the date of surgery to the date of death or last follow-up.

Reverse transcription-quantitative polymerase chain reaction (RT-qPCR). Total RNA was extracted from HCC frozen tissue samples using TRIzol (Invitrogen; Thermo Fisher Scientific, Inc., Waltham, MA, USA) reagent, and cDNA was synthesized by using PrimeScript RT reagent kit (Takara Bio, Inc., Otsu, Japan) according to the manufacturer's instructions. The temperature protocol of reverse transcription was as follows: $42^{\circ} \mathrm{C}$ for $2 \mathrm{~min}$ in order to remove the contamination of genomic DNA, then reverse transcription at $37^{\circ} \mathrm{C}$ for $15 \mathrm{~min}$ and $85^{\circ} \mathrm{C}$ for $5 \mathrm{sec}$. qPCR analysis was performed using SYBR Premix Ex Taq (Takara Bio, Inc., Otsu, Japan), according to the manufacturer's instructions. Each well was mixed with $15 \mu 1$ Master Mix (SYBR ${ }^{\circledR}$ Green PCR Master Mix; Applied Biosystems; Thermo Fisher Scientific, Inc.). The protocol was performed with an initial denaturation step at $95^{\circ} \mathrm{C}$ for $10 \mathrm{~min}$, followed by 40 cycles of denaturation at $95^{\circ} \mathrm{C}$ for $2 \mathrm{sec}$, annealing at $55^{\circ} \mathrm{C}$ for $5 \mathrm{sec}$ and extension at $72^{\circ} \mathrm{C}$ for $15 \mathrm{sec}$. The sequences of the primers used were: RECQL4 (158 bp) forward, 5'-TCAACATGAAGCAGAAACACTAC-3' and reverse, 5'-CTGCTCGTTCAGGAAACAAGACT-3'; and $\beta$-actin (142 bp) forward, 5'-GACAGGATGCAGAAGGAG ATTACT-3' and reverse, 5'-TGATCCACATCTGCTGGA AGGT-3'. The levels of RECQL4 were normalized to the levels of $\beta$-actin expression using the $2^{-\Delta \Delta \mathrm{Cq}}$ methodas reported by Livak and Schmittgen (22).

Statistical analysis. All quantitative data are expressed as the mean \pm standard deviation and were analyzed using an independent t-test. Categorical variables were compared using $\chi^{2}$ test. The DFS and OS rates were calculated using the Kaplan-Meier method, and comparisons of survival curves between groups were assessed with log-rank test. Multivariate analysis was performed using the Cox proportional hazards model, and only variables that were statistically significant in univariate analysis were included in this model. All statistical analyses were performed using SPSS13.0 statistical software (SPSS, Inc., Chicago, IL, USA). $\mathrm{P}<0.05$ was considered to indicate a statistically significant difference.

\section{Results}

Expression of RECQL4 $\mathrm{mRNA}$ is upregulated in human HCC tissues. RECQL4 mRNA expression was examined in 205 samples of fresh HCC tissues and their corresponding ANLT by RT-qPCR. As shown in Fig. 1A, the relative expression of RECQL4 mRNA in HCC cancer tissues (1.10 \pm 0.07$)$ was significantly higher compared with ANLT $(0.33 \pm 0.04)$ when normalized to $\beta$-actin $(\mathrm{P}<0.001)$. The RECQL4 mRNA levels were increased in 141 cases $(68.8 \%)$, but decreased in 64 cases $(31.2 \%)$. Notably, the upregulation of RECQL4 mRNA expression and the increase of serum AFP levels did not completely overlap. High RECQL4 expression along with high serum AFP level was detected in 96 cases (46.83\%), high serum AFP level alone was detected in 34 cases (16.59\%), and upregulation of RECQL4 but not AFP was detected in 45cases (21.95\%; Fig. 1B). These results indicated that RECQL4 might be a novel histological biomarker for HCC. When these two markers were combined, the HCC diagnosis rate was increased to $85.37 \%$.

Association between RECQL4 $\mathrm{mRNA}$ and clinical pathological characteristics of HCC. To further investigate the association between RECQL4 mRNA expression and clinicopathological parameters of $\mathrm{HCC}$, the characteristics of the 
Table I. Association between clinicopathological characteristics and RECQL4 mRNA expression in HCC.

\begin{tabular}{|c|c|c|c|c|c|}
\hline \multirow[b]{2}{*}{ Variable } & \multirow[b]{2}{*}{ Patients, $\mathrm{n}$} & \multicolumn{2}{|c|}{ RECQL4 expression } & \multirow[b]{2}{*}{$\chi^{2}$} & \multirow[b]{2}{*}{ P-value } \\
\hline & & Low, n (\%) & High, n (\%) & & \\
\hline Age, years & & & & 0.448 & 0.503 \\
\hline$\leq 55$ & 138 & $41(29.7)$ & $97(70.3)$ & & \\
\hline$>55$ & 67 & $23(34.3)$ & $44(65.7)$ & & \\
\hline Sex & & & & 0.892 & 0.345 \\
\hline Male & 172 & $56(32.6)$ & $116(67.4)$ & & \\
\hline Female & 33 & $8(24.2)$ & $25(75.8)$ & & \\
\hline Family history & & & & 0.082 & 0.775 \\
\hline No & 172 & $53(30.8)$ & $119(69.2)$ & & \\
\hline Yes & 33 & $11(33.3)$ & $22(66.7)$ & & \\
\hline Alcohol consumption & & & & 0.554 & 0.457 \\
\hline No & 101 & 34 (33.7) & $67(66.3)$ & & \\
\hline Yes & 104 & $30(28.8)$ & $74(71.2)$ & & \\
\hline HBsAg & & & & 1.454 & 0.228 \\
\hline Negative & 41 & $16(39.0)$ & $25(61.0)$ & & \\
\hline Positive & 164 & $48(29.3)$ & $116(70.7)$ & & \\
\hline $\mathrm{AFP}, \mathrm{ng} / \mathrm{ml}$ & & & & 4.246 & 0.039 \\
\hline$\leq 100$ & 75 & $30(40.0)$ & $45(60.0)$ & & \\
\hline$>100$ & 130 & $34(26.2)$ & $96(73.8)$ & & \\
\hline Cirrhosis & & & & 2.715 & 0.099 \\
\hline No & 20 & $3(15.0)$ & $17(85.0)$ & & \\
\hline Yes & 185 & $61(33.0)$ & $124(67.0)$ & & \\
\hline Tumor size, cm & & & & 7.852 & 0.005 \\
\hline$\leq 6$ & 89 & 37 (41.6) & $52(58.4)$ & & \\
\hline$>6$ & 116 & $27(23.3)$ & $89(76.7)$ & & \\
\hline Tumor number & & & & 0.509 & 0.475 \\
\hline Single & 137 & $45(32.8)$ & $92(67.2)$ & & \\
\hline Multiple & 68 & $19(27.9)$ & $49(72.1)$ & & \\
\hline BCLC stage & & & & 6.293 & 0.012 \\
\hline $0-\mathrm{A}$ & 92 & $37(40.2)$ & $55(59.8)$ & & \\
\hline B-C & 113 & $27(23.9)$ & $86(76.1)$ & & \\
\hline Metastasis & & & & 0.789 & 0.374 \\
\hline No & 176 & $57(32.4)$ & $119(67.6)$ & & \\
\hline Yes & 29 & $7(24.1)$ & $22(75.9)$ & & \\
\hline Recurrence & & & & 1.737 & 0.188 \\
\hline No & 135 & $38(28.1)$ & $97(71.9)$ & & \\
\hline Yes & 70 & $26(37.1)$ & $44(62.9)$ & & \\
\hline
\end{tabular}

RECQL4, ATP-dependent DNA helicase Q4; HBsAg, hepatitis B surface antigen; AFP, alpha-fetoprotein; BCLC, Barcelona Clinic Liver Cancer; Metastasis, distant metastasis or lymph node metastasis.

205 HCC patients were analyzed. As shown in Table I, the level of RECQL4 mRNA expression was positively associated with AFP level $(>100 \mathrm{ng} / \mathrm{ml})\left(\chi^{2}=4.246, \mathrm{P}=0.039\right)$, tumor size $(>6 \mathrm{~cm})\left(\chi^{2}=7.852, \mathrm{P}=0.005\right)$, and BCLC stage $\left(\chi^{2}=6.293\right.$, $\mathrm{P}=0.012)$, but was not associated with age ( $>55$ years), gender, family history, alcohol consumption, HBsAg expression, liver cirrhosis, tumor number, metastasis or postoperative recurrence (all $\mathrm{P}>0.05$ ).
Univariate analysis of prognostic factors of DFS and OS. Kaplan-Meier survival analysis revealed that patients expressing high levels of RECQL4 mRNA had significantly shorter DFS and OS times compared with those with low RECQL4 mRNA expression ( $\log$-rank test: $\mathrm{P}=0.002$, and $\mathrm{P}=0.001$, respectively; Fig. 2). Mean DFS and OS in the high-RECQL4 mRNA expression group was 34.23 months [95\% confidence interval (CI), 28.42-40.03] and 38.37 months (95\% CI, 
A

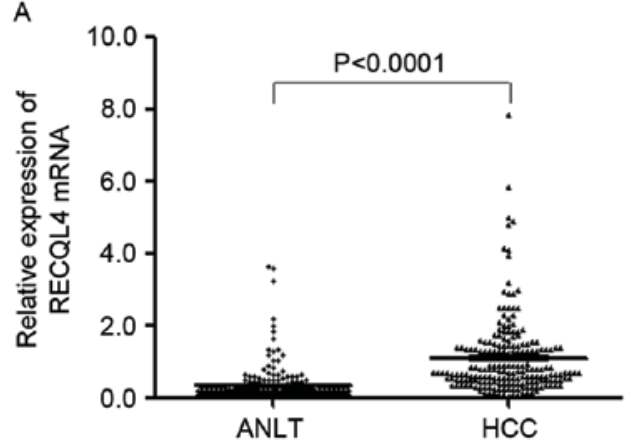

B

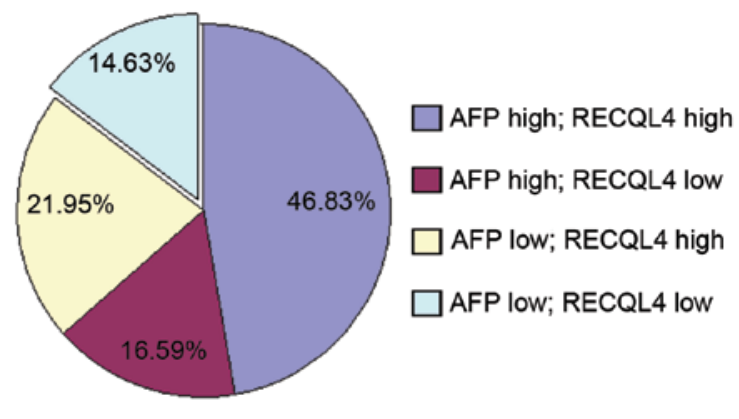

Figure 1. Level of RECQL4 mRNA expression in HCC tissues and ANLT. (A) Reverse transcription-quantitative polymerase chain reaction analysis of RECQL4 was performed on 205 paired HCC cancer tissues and ANLT. The levels of RECQL4 mRNA expression were scored and compared. For each sample, the relative RECQL4 mRNA level was normalized to the level of $\beta$-actin. (B) The distribution of RECQL4 mRNA and serum AFP levels in the 205 HCC specimens. The percentage of specimens with high and low RECQL4 expression and AFP-positive expression are indicated. HCC, hepatocellular carcinoma; ANLT, adjacent normal liver tissues; RECQL4, ATP-dependent DNA helicase Q4; AFP, $\alpha$-fetoprotein.

A

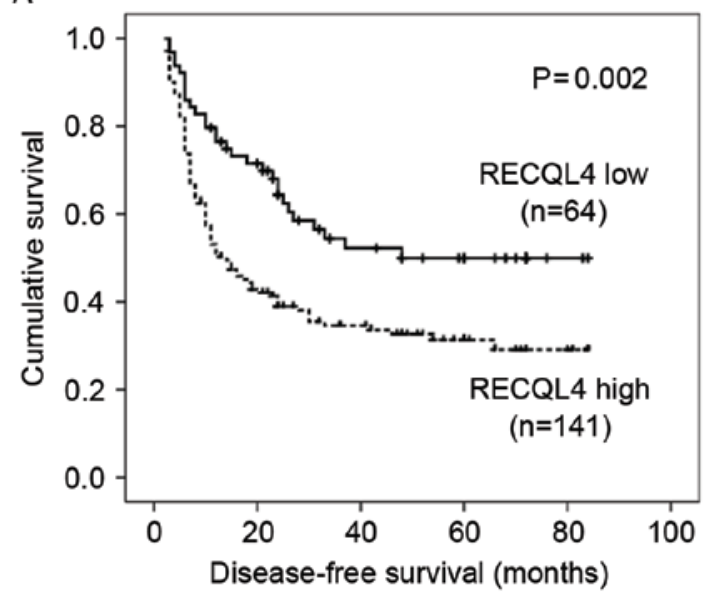

B

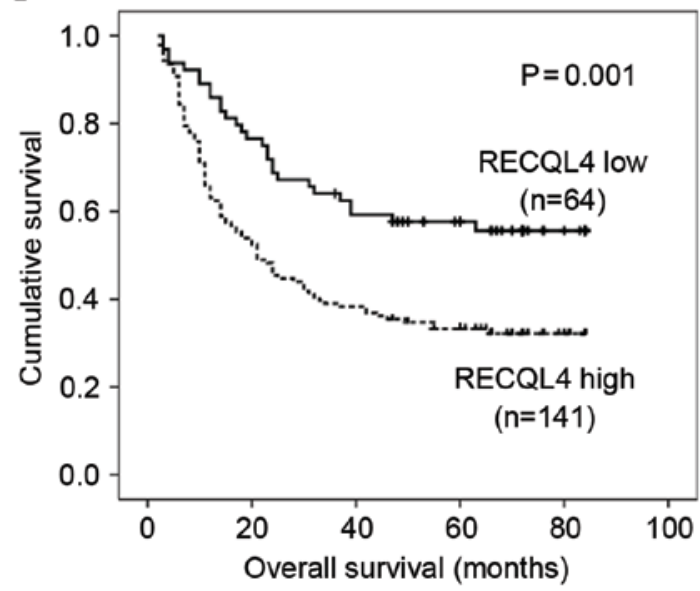

Figure 2. Association between RECQL4 expression and DFS or OS. Kaplan-Meier analysis revealed significantly shorter (A) DFS and (B) OS times in patients with hepatocellular carcinoma with high RECQL4 expression compared with patients with low RECQL4 expression. The solid line represents patients with low RECQL4 expression, and the dashed line represents patients with high RECQL4 expression. OS, overall survival; DFS, disease-free survival; RECQL4, ATP-dependent DNA helicase Q4.

32.84-43.90) respectively, compared with 50.73 months $(95 \%$ CI, 41.88-59.58) and 56.31 months (95\% CI, 48.33-64.30) in the low-RECQL4 mRNA expression group $(\mathrm{P}=0.002$ and $\mathrm{P}=0.001$, respectively; Table II). Apart from high RECQL4 mRNA expression, other factors, including size of tumor $(>6 \mathrm{~cm})$, multiple tumor number, stage B-C (according to BCLC staging) and metastasis, were also strongly associated with a shorter DFS and OS, and recurrence was associated with a shorter OS (Table II).

Multivariate analysis of independent predictors on DFS and $O S$. To evaluate the predictive roles of these factors in HCC prognosis further (other than recurrence factor, which was measured only for OS), high RECQL4 mRNA expression and other clinical pathological parameters [size of tumor $(>6 \mathrm{~cm})$, multiple tumor number, BCLC stage B-C and metastasis] that were identified to be statistically significant by univariate analysis were analyzed using the multivariate Cox proportional hazards model for DFS and OS. Cox multivariate analysis revealed that high RECQL4 mRNA expression (HR, 1.635; $95 \% \mathrm{CI}, 1.062-2.515 ; \mathrm{P}=0.025)$, as well as size of tumor $(>6 \mathrm{~cm})$
(HR, 2.670; 95\% CI, 1.704-4.183; P<0.001), BCLC stage B-C (HR, 1.835; 95\% CI, 1.116-3.018; $\mathrm{P}=0.017$ ) were independent predictors for DFS (Table III). High RECQL4 mRNA expression (HR, 1.618; 95\% CI, 1.050-2.493; $\mathrm{P}=0.029)$, size of tumor (>6 cm) (HR, 2.536; 95\% CI, 1.621-3.967; P<0.001), BCLC stage B-C (HR,1.679; 95\% CI, 1.128-2.760; P=0.041) and disease recurrence (HR, 2.832; 95\% CI, 1.827-4.391; $\mathrm{P}<0.001$ ) were independent predictors for OS (Table III).

\section{Discussion}

RECQL4 expression is associated with cancer-prone syndromes and premature aging. RECQL4 shares homology in its $\mathrm{N}$-terminal domain with the yeast replication initiation protein Sld2, which participates in DNA replication initiation $(13-15,23,24)$. Unlimited replicative potential is a hallmark of HCC cells. In the present study, the expression of RECQL4 mRNA was investigated in HCC tissues, and RECQL4 mRNA was found to be highly expressed in liver cancer tissues compared with ANLT. Similar to other oncogenes, overexpression of RECQL4 may confer an unlimited 
Table II. Association between RECQL4 mRNA expression, clinical parameters and disease-free/overall survival.

\begin{tabular}{|c|c|c|c|c|c|c|c|}
\hline \multirow[b]{2}{*}{ Clinical characteristics } & \multirow[b]{2}{*}{ Patients, $n$} & \multicolumn{3}{|c|}{ Disease-free survival } & \multicolumn{3}{|c|}{ Overall survival } \\
\hline & & Mean, months & $95 \% \mathrm{CI}$ & P-value & Mean, months & $95 \% \mathrm{CI}$ & P-value \\
\hline RECQL4 mRNA & & & & 0.002 & & & 0.001 \\
\hline Low & 64 & 50.73 & $41.88-59.58$ & & 56.31 & $48.33-64.30$ & \\
\hline High & 141 & 34.23 & $28.42-40.03$ & & 38.37 & $32.84-43.90$ & \\
\hline Age, years & & & & 0.646 & & & 0.634 \\
\hline$\leq 55$ & 138 & 38.09 & $32.06-44.11$ & & 43.70 & $37.84-49.57$ & \\
\hline$>55$ & 67 & 40.68 & $32.17-49.19$ & & 45.85 & $37.62-54.08$ & \\
\hline Sex & & & & 0.299 & & & 0.141 \\
\hline Female & 33 & 45.30 & $31.98-58.63$ & & 53.41 & $41.20-65.62$ & \\
\hline Male & 172 & 37.82 & $32.53-43.10$ & & 42.81 & $37.63-47.50$ & \\
\hline Family history & & & & 0.155 & & & 0.115 \\
\hline No & 172 & 37.20 & $31.90-42.50$ & & 42.85 & $37.65-48.06$ & \\
\hline Yes & 33 & 48.00 & $35.61-60.39$ & & 53.12 & $41.56-64.68$ & \\
\hline Alcohol consumption & & & & 0.139 & & & 0.081 \\
\hline No & 101 & 43.60 & $36.17-51.04$ & & 48.07 & $41.02-55.13$ & \\
\hline Yes & 104 & 34.88 & $28.50-41.26$ & & 40.51 & $34.20-46.81$ & \\
\hline $\mathrm{HBsAg}$ & & & & 0.652 & & & 0.616 \\
\hline Negative & 41 & 35.44 & $25.01-45.87$ & & 41.84 & $31.60-52.09$ & \\
\hline Positive & 164 & 39.74 & $34.18-45.30$ & & 44.61 & $39.30-49.93$ & \\
\hline AFP, ng/ml & & & & 0.200 & & & 0.209 \\
\hline$\leq 100$ & 75 & 42.88 & $35.17-50.58$ & & 48.09 & $40.94-55.24$ & \\
\hline$>100$ & 130 & 37.19 & $30.73-43.65$ & & 41.20 & $35.06-47.34$ & \\
\hline Cirrhosis & & & & 0.694 & & & 0.824 \\
\hline No & 20 & 35.40 & $19.79-51.01$ & & 41.85 & 27.14-56.56 & \\
\hline Yes & 185 & 39.23 & $34.05-44.14$ & & 44.24 & $39.27-49.21$ & \\
\hline Tumor size, $\mathrm{cm}$ & & & & $<0.001$ & & & $<0.001$ \\
\hline$\leq 6$ & 89 & 57.76 & $50.66-64.85$ & & 62.66 & $56.55-68.77$ & \\
\hline$>6$ & 116 & 25.25 & $19.59-30.91$ & & 29.59 & 24.04-35.14 & \\
\hline Tumor number & & & & $<0.001$ & & & $<0.001$ \\
\hline Single & 137 & 44.85 & $38.77-50.92$ & & 50.84 & $45.03-56.65$ & \\
\hline Multiple & 68 & 26.57 & $19.03-34.11$ & & 31.75 & $24.25-39.25$ & \\
\hline BCLC stage & & & & $<0.001$ & & & $<0.001$ \\
\hline $0-\mathrm{A}$ & 92 & 54.29 & 47.04-61.54 & & 60.09 & $53.47-66.72$ & \\
\hline $\mathrm{B}-\mathrm{C}$ & 113 & 26.41 & $20.70-32.12$ & & 31.76 & 25.94-37.58 & \\
\hline Metastasis & & & & 0.023 & & & 0.048 \\
\hline No & 176 & 41.15 & $35.76-46.53$ & & 45.63 & $40.51-50.75$ & \\
\hline Yes & 29 & 23.56 & $14.71-32.42$ & & 34.12 & $22.84-45.39$ & \\
\hline Recurrence & & & & & & & $<0.001$ \\
\hline No & 135 & & & & 34.55 & $28.81-40.28$ & \\
\hline Yes & 70 & & & & 63.22 & $56.70-69.75$ & \\
\hline
\end{tabular}

CI, confidence interval; HBsAg, hepatitis B surfaceantigen; AFP, alpha-fetoprotein; BCLC, Barcelona Clinic Liver Cancer; Metastasis, distant metastasis or lymph node metastasis; RECQL4, ATP-dependent DNA helicase Q4.

proliferative potential to hepatoma cells and promote hepatocellular tumorigenesis $(20,21)$.

The upregulation of RECQL4 mRNA expression in HCC tissues was positively associated with serum AFP levels
( $>100 \mathrm{ng} / \mathrm{ml}$ ). Despite being a recommended tumor marker for HCC screening, detecting AFP alone is not optimal for the surveillance or diagnosis of HCC, owing to its deficiencies in the sensitivity and specificity of testing (25). Therefore, the 
Table III. Cox multivariate proportional hazards model of independent predictors on disease-free and overall survival.

A, Disease-free survival

\begin{tabular}{lrr}
\hline Parameter & HR $(95 \%$ CI & P-value \\
\hline Tumor size, cm ( $\leq 6$ vs. $>6$ cm) & $2.670(1.704-4.183)$ & $<0.001$ \\
Tumor number (single vs. multiple) & $1.092(0.692-1.723)$ & 0.707 \\
Metastasis (no vs. yes) & $1.116(0.685-1.816)$ & 0.660 \\
BCLC stage (0-A vs. B-C) & $1.835(1.116-3.018)$ & 0.017 \\
RECQL4 mRNA (low vs. high) & $1.635(1.062-2.515)$ & 0.025 \\
\hline
\end{tabular}

B, Overall survival

\begin{tabular}{lrr}
\hline Parameter & HR (95\% CI) & P-value \\
\hline Tumor size, cm ( $\leq 6$ vs. $>6$ cm) & $2.536(1.621-3.967)$ & $<0.001$ \\
Tumor number (single vs. multiple) & $1.033(0.652-1.637)$ & 0.890 \\
Metastasis (no vs. yes) & $1.212(0.742-1.981)$ & 0.443 \\
BCLC stage (0-A vs. B-C) & $1.679(1.021-2.760)$ & 0.041 \\
Recurrence (no vs. yes) & $2.832(1.827-4.391)$ & $<0.001$ \\
RECQL4 mRNA (low vs. high) & $1.618(1.050-2.493)$ & 0.029 \\
\hline
\end{tabular}

HR, hazard ratio; CI, confidence interval; metastasis, distant metastasis or lymph node metastasis; BCLC, Barcelona Clinic Liver Cancer; RECQL4, ATP-dependent DNA helicase Q4.

identification of novel molecular markers with superior sensitivity and specificity is urgently required. The present study indicated that RECQL4 maybe a potential novel biomarker for $\mathrm{HCC}$ diagnosis, and the positive rate of $\mathrm{HCC}$ diagnosis may be improved to $85.37 \%$ by detecting a combination of AFP and RECQL4. In addition, the increase in the level of RECQL4 mRNA expression was also positively associated with large tumor size $(>6 \mathrm{~cm})$ and stage B-C disease. Therefore, the authors hypothesize that RECQL4 contributes to malignant progression of HCC.

Under univariate analysis, high RECQL4 expression, tumor size $>6 \mathrm{~cm}$, multiple tumor nodules, metastasis and stage B-C disease were identified to associate with poor DFS and OS times of HCC patients. Large tumors $(>5 \mathrm{~cm})$ and multiple tumors are more closely associated with bilobar tumor involvement, tumor invasion of adjacent organs, microvascular invasion and histologically positive margins (26). In addition, tumor size $(>5 \mathrm{~cm})$ and multinodular disease were reported to significantly increase the risk of postoperative recurrence (26-28). The data from the present study demonstrated that intermediate and advanced BCLC stage is predictive of a poorer prognosis for HCC patients following surgical resection. For HCC patients who received no anticancer treatment, the severity of the BCLC stage is strongly consistent with a poorer median survival as well (29). Notably, high RECQL4 mRNA expression in HCC patients was also predictive of a significantly shorter survival compared with patients with low RECQL4 expression. These clinical data suggest that RECQL4 maybe a useful prognostic marker for HCC.

In the present study, notable predictive factors of survival for HCC were identified. High RECQL4 expression, size of tumor
$>6 \mathrm{~cm}$, and stage B-C disease were shown to be independent predictors of DFS and OS for HCC patients. Large tumor size ( $>5 \mathrm{~cm}$ ) has been consistently shown to be an independent prognostic marker in HCC patients $(30,31)$. Generally, HCC patients with larger tumors $(>6 \mathrm{~cm})$ have a poorer prognosis. Since an inaccurate prediction can bring about severe harm to patients, as independent predictors for the outcomes of $\mathrm{HCC}$, the expression of RECQL4, tumor size and BCLC stage can aid hepatologists in providing more accurate prognosis predictions, improved risk assessment assessing and in planning therapeutic trials.

In conclusion, the results of the current study found that the expression of RECQL4 mRNA was significantly higher in HCC tissue compared with adjacent normal liver tissues. Whether the upregulation of RECQL4 expression contributes to hepatocarcinogenesis will be a key research question to be investigated in future experiments. It may be possible to use RECQL4 as a novel biomarker for HCC diagnosis. This retrospective study also provides evidence that RECQL4 may serve as an independent predictor of prognosis for HCC patients. Furthermore, targeting RECQL4 may provide a promising strategy for the treatment of HCC patients with high RECQL4 expression. However, further research is required to elucidate the underlying molecular mechanism of HCC.

\section{Acknowledgements}

The present study was supported in part by grants from the National Natural Science Foundation of China (grant no. 81773148), and the Innovation and Entrepreneurship Project of University Students in Guangxi (grant nos. 201610598047 and 201610601006). 


\section{References}

1. Torre LA, Bray F, Siegel RL, Ferlay J, Lortet-Tieulent J and Jemal A: Global cancer statistics, 2012. CA Cancer J Clin 65: 87-108, 2015

2. Greene FL, Page DL, Fleming ID, Fritz AG, Balch CM, Haller DG and Morrow M (eds): AJCC Cancer Staging Manual. 6th edition. Springer, Chicago, IL, 2002.

3. A new prognostic system for hepatocellular carcinoma: A retrospective study of 435 patients: The Cancer of the Liver Italian Program (CLIP) investigators. Hepatology 28: 751-755, 1998.

4. Llovet JM, Brú C and Bruix J: Prognosis of hepatocellular carcinoma: The BCLC staging classification. Semin Liver Dis 19: 329-338, 1999

5. Liao W, Liu W, Yuan Q, Liu X, Ou Y, He S, Yuan S, Qin L, Chen Q, Nong K, et al: Silencing of DLGAP5 by siRNA significantly inhibits the proliferation and invasion of hepatocellular carcinoma cells. PLoS One 8: e80789, 2013.

6. Liao W, Liu W, Liu X, Yuan Q, Ou Y, Qi Y, Huang W, Wang Y and Huang J: Upregulation of FAM83D affects the proliferation and invasion of hepatocellular carcinoma. Oncotarget 6 : 24132-24147, 2015.

7. Croteau DL, Singh DK, Hoh Ferrarelli L, Lu H and Bohr VA: RECQL4 in genomic instability and aging. Trends Genet 28 624-631, 2012.

8. Hanahan D and Weinberg RA: Hallmarks of cancer: The next generation. Cell 144: 646-674, 2011

9. Petkovic M, Dietschy T, Freire R, Jiao R and Stagljar I: The human Rothmund-Thomson syndrome gene product, RECQL4, localizes to distinct nuclear foci that coincide with proteins involved in the maintenance of genome stability. J Cell Sci 118 4261-4269, 2005.

10. Kitao S, Shimamoto A, Goto M, Miller RW, Smithson WA, Lindor NM and Furuichi Y: Mutations in RECQL4 cause a subset of cases of Rothmund-Thomson syndrome. Nat Genet 22: 82-84, 1999.

11. Siitonen HA, Kopra O, Kääriäinen H, Haravuori H, Winter RM, Säämänen AM, Peltonen L and Kestilä M: Molecular defect of RAPADILINO syndrome expands the phenotype spectrum of RECQL diseases. Hum Mol Genet 12: 2837-2844, 2003.

12. Van Maldergem L, Siitonen HA, Jalkh N, Chouery E, De Roy M, Delague V, Muenke M, Jabs EW, Cai J, Wang LL, et al: Revisiting sis-radial ray hypoplasia association: Baller-Gerold syndrome caused by mutations in the RECQL4 gene. J Med Genet 43: 148-152, 2006.

13. Sangrithi MN, Bernal JA, Madine M, Philpott A, Lee J, Dunphy WG and Venkitaraman AR: Initiation of DNA replication requires the RECQL4 protein mutated in Rothmund-Thomson syndrome. Cell 121: 887-898, 2005.

14. Xu X and Liu Y: Dual DNA unwinding activities of the Rothmund-Thomson syndrome protein, RECQ4. EMBO J 28: 568-577, 2009.

15. Collart C, Allen GE, Bradshaw CR, Smith JC and Zegerman P: Titration of four replication factors is essential for the Xenopus laevis midblastula transition. Science 341: 893-896, 2013.

16. Fan W and Luo J: RecQ4 facilitates UV light-induced DNA damage repair through interaction with nucleotide excision repair factor xeroderma pigmentosum group A (XPA). J Biol Chem 283: 29037-29044, 2008.

17. Schurman SH, Hedayati M, Wang Z, Singh DK, Speina E, Zhang Y, Becker K, Macris M, Sung P, Wilson DM III, et al: Direct and indirect roles of RECQL4 in modulating base excision repair capacity. Hum Mol Genet 18: 3470-3483, 2009.
18. Singh DK, Karmakar P, Aamann M, Schurman SH, May A Croteau DL, Burks L, Plon SE and Bohr VA: The involvement of human RECQL4 in DNA double-strand break repair. Aging Cell 9: 358-371, 2010.

19. Maire G, Yoshimoto M, Chilton-MacNeill S, Thorner PS, Zielenska M and Squire JA: Recurrent RECQL4 imbalance and increased gene expression levels are associated with structural chromosomal instability in sporadic osteosarcoma. Neoplasia 11: 260-268, 2009

20. Su Y, Meador JA, Calaf GM, Proietti De-Santis L, Zhao Y, Bohr VA and Balajee AS: Human RecQL4 helicase plays critical roles in prostate carcinogenesis. Cancer Res 70: 9207-9217, 2010.

21. Fang H, Nie L, Chi Z, Liu J, Guo D, Lu X, Hei TK, Balajee AS and Zhao Y: RecQL4 helicase amplification is involved in human breast tumorigenesis. PLoS One 8: e69600, 2013.

22. Livak KJ and Schmittgen TD: Analysis of relative gene expression data using real-time quantitative PCR and the 2(-Delta Delta C(T)) method. Methods 25: 402-408, 2001.

23. Zegerman P and Diffley JF: Phosphorylation of Sld 2 and Sld 3 by cyclin-dependent kinases promotes DNA replication in budding yeast. Nature 445: 281-285, 2007.

24. Xu X, Rochette PJ, Feyissa EA, Su TV and Liu Y: MCM10 mediates RECQ4 association with MCM2-7 helicase complex during DNA replication. EMBO J 28: 3005-3014, 2009.

25. Bruix J and Sherman M; American Association for the Study of Liver Diseases: Management of hepatocellular carcinoma: An update. Hepatology 53: 1020-1022, 2011.

26. Ng KK, Vauthey JN, Pawlik TM, Lauwers GY, Regimbeau JM, Belghiti J, Ikai I, Yamaoka Y, Curley SA, Nagorney DM, et al: Is hepatic resection for large or multinodular hepatocellular carcinoma justified? Results from a multi-institutional database. Ann Surg Oncol 12: 364-373, 2005.

27. Kow AW, Kwon CH, Song S, Shin M, Kim JM and Joh JW: Risk factors of peritoneal recurrence and outcome of resected peritoneal recurrence after liver resection in hepatocellular carcinoma: Review of 1222 cases of hepatectomy in a tertiary institution. Ann Surg Oncol 19: 2246-2255, 2012.

28. Ishizawa T, Hasegawa K, Aoki T, Takahashi M, Inoue Y, Sano K, Imamura $\mathrm{H}$, Sugawara Y, Kokudo $\mathrm{N}$ and Makuuchi M: Neither multiple tumors nor portal hypertension are surgical contraindications for hepatocellular carcinoma. Gastroenterology 134: 1908-1916, 2008

29. Giannini EG, Farinati F, Ciccarese F, Pecorelli A, Rapaccini GL, Di Marco M, Benvegnù L, Caturelli E, Zoli M, Borzio F, et al: Prognosis of untreated hepatocellular carcinoma. Hepatology 61: 184-190, 2015.

30. Liu PH, Hsu CY, Hsia CY, Lee YH, Su CW, Huang YH, Lee FY, Lin HC and Huo TI: Prognosis of hepatocellular carcinoma: Assessment of eleven staging systems. J Hepatol 64: 601-608, 2016.

31. Gomaa AI, Hashim MS and Waked I: Comparing staging systems for predicting prognosis and survival in patients with hepatocellular carcinoma in Egypt. PLoS One 9: e90929, 2014.

This work is licensed under a Creative Commons Attribution-NonCommercial-NoDerivatives 4.0 International (CC BY-NC-ND 4.0) License. 